\title{
Micro-geographic variation in burrow use of Agassiz's desert tortoises in the Sonoran Desert of California
}

\author{
Kristy L. Cummings ${ }^{1}$, Jeffrey E. Lovich ${ }^{1}$, Shellie R. Puffer ${ }^{1}$, Terence R. Arundel ${ }^{1}$ \& Kathleen D. \\ Brundige $^{2}$
}

${ }^{1}$ U. S. Geological Survey, Southwest Biological Science Center, 2255 North Gemini Dr. Flagstaff, AZ 86001, USA

${ }^{2}$ Coachella Valley Conservation Commission, 73-710 Fred Waring Drive, Suite 200, Palm Desert, CA 92260-2516, USA

\begin{abstract}
Little has been published regarding the burrowing habits of Agassiz's desert tortoises (Gopherus agassizii) in the Sonoran Desert of California. We monitored the interactions of tortoises with their burrows, and other tortoises, via radio-telemetry at two nearby sites between the Cottonwood and Orocopia Mountains, from 2015-2018. We examined how annual cycles of drought and non-drought years, behaviourally affected how tortoises use their burrows (i.e., burrow fidelity, cohabitation, and location), including the timing of the tortoise brumation period. Burrow locations were strongly dependent on local geology and topography, with a tendency to orientate in conformance with the general aspect of the landscape. The timing of brumation was similar to records for $G$. agassizii throughout their range (with a few exceptions). There was no difference in the estimated number of burrows used per 30 days between the active seasons (2017 and 2018) at the Orocopia site, despite the occurrence of drought in 2018.
\end{abstract}

Keywords: Gopherus agassizii, Mojave Desert, hibernation, brumation, drought

\section{INTRODUCTION}

$\mathrm{T}$ he threatened Agassiz's desert tortoise (Gopherus agassizii) occupies portions of the Mojave and Sonoran Deserts, north and west of the Colorado River. The habitat of G. agassizii has historically been described as areas without a great deal of topographic diversity including valleys, alluvial fans, and bajadas (outwash plains) interspersed with desert washes (Berry et al., 2002; Ernst \& Lovich, 2009; Murphy et al., 2011). In contrast, its congener, Morafka's desert tortoise (Gopherus morafkai), that occupies other parts of the Sonoran Desert, south and east of the Colorado River in Arizona and into northern Mexico, tends to utilise rocky hill slopes and deeply-incised washes with caliche layers that extend out onto valley floors (Germano et al., 1994; Murphy et al., 2011; Riedle et al., 2008). Both species show a high degree of site fidelity to their burrows with relatively small home ranges (Averill-Murray et al., 2002b; Freilich et al., 2000). We compared burrow use of $G$. agassizii between two sites in the Sonoran Desert of California.

Underground refugia are extremely important for the survival of $G$. agassizii, and the species spends as much as 98 percent of their annual cycle sheltering in self-constructed burrows (Nagy \& Medica, 1986) to avoid environmental extremes that characterise the region (Bulova, 2002; Mack et al., 2015; Zimmerman et al., 1994). Burrow use varies annually and seasonally. Tortoises typically occupy multiple burrows in a given year, in different substrates, and burrows are usually characterised by their half-dome-shaped entrance and large mound of excavated material at the opening (Burge, 1978; Luckenbach, 1982). Tortoises are believed to select burrows based on a variety of factors that affect their suitability for survival including slope, aspect, and proper soil type for digging and stability (Anderson et al., 2000; Bulova, 2002; Ernst \& Lovich, 2009; Lovich \& Daniels, 2000; Stager et al., 2017). Proper placement and construction of a burrow has important fitness consequences for a tortoise because they provide protection from predators, thermal extremes, floods, fires, and other mortality factors (Kinlaw, 1999; Lovich \& Daniels, 2000).

Burrows are not just important to the desert tortoises; burrows also provide shelter for many other species, some of which cannot dig burrows of their own, like burrowing owls (Athene cunicularia) (Agha et al., 2017; Crowe \& Longshore, 2013; Ernst \& Lovich, 2009; Lovich et al., 2018a; Luckenbach, 1982). Burrow commensals of tortoises include a variety of animals such as lizards, snakes, birds, rodents, spiders, and insects (Agha et al., 2017; Burge, 1978; Kinlaw, 1999; Kinlaw \& Grasmueck, 2012; Lovich et al., 2018a; Luckenbach, 1982; Woodbury 


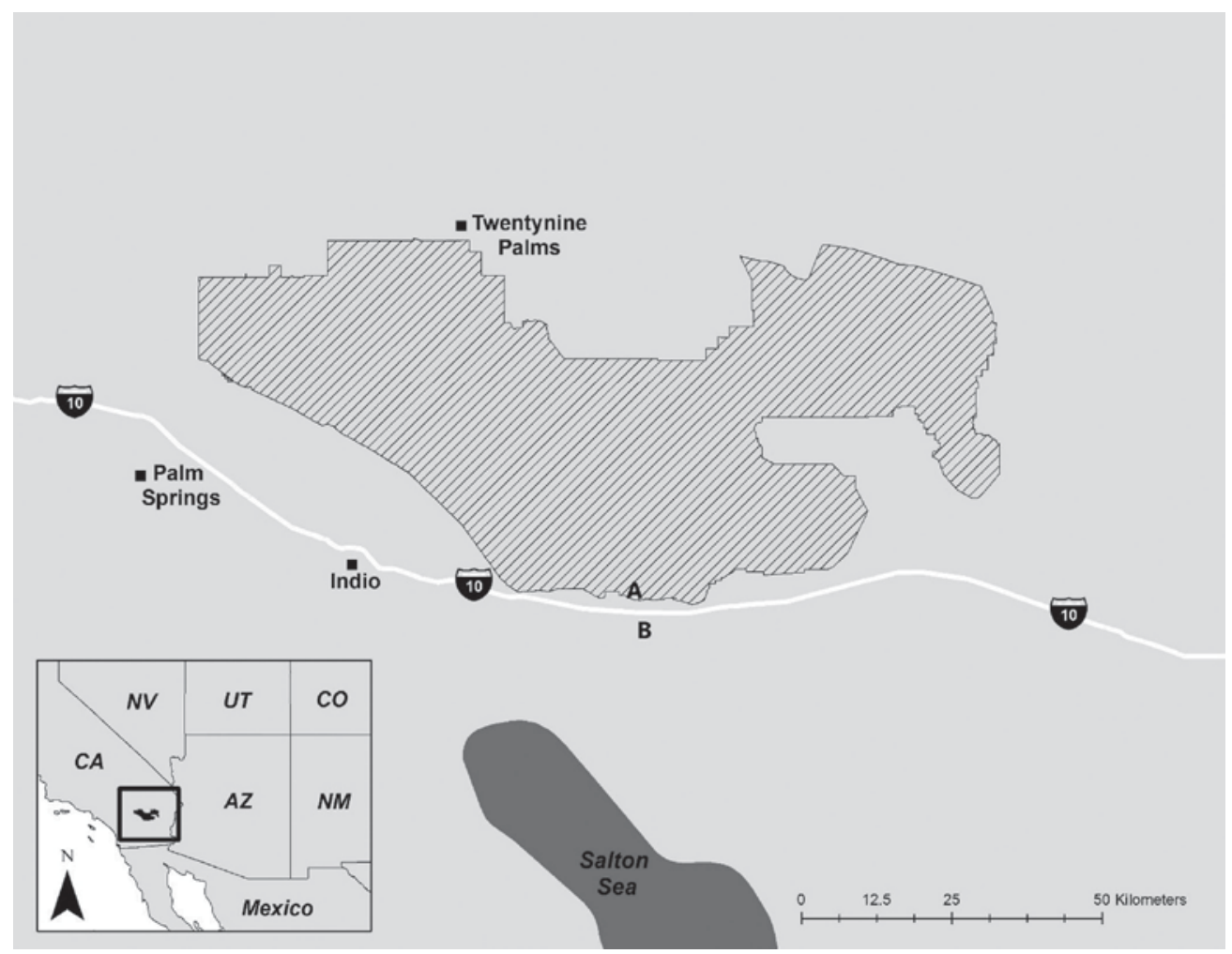

Figure 1. The Cottonwood (A) and Orocopia (B) study sites in reference to Joshua Tree National Park (lined) and the Salton Sea (shaded). Interstate 10 runs east to west between the two sites. The study area is highlighted in the box in California. $\mathrm{CA}=$ California, $\mathrm{AZ}=$ =Arizona, NM=New Mexico, $\mathrm{CO}=$ Colorado, UT=Utah, NV=Nevada, USA.

\& Hardy, 1948). Commensal species utilise tortoise burrows in numerous ways, sometimes contributing to a trophic bottom-up effect in active tortoise burrows, thus attracting other species to the burrow (Agha et al., 2017; Currylow et al., 2016; Lips, 1991; Walde et al., 2015).

Because drought is an overriding driver in desert ecosystems, burrow use should be affected under drier than usual conditions. Noy-Meir (1973) stated that "desert ecosystems are water-controlled ecosystems with infrequent, discrete, and largely unpredictable water in-puts". All trophic levels are affected during times of decreased precipitation on both micro- (i.e., individual organisms) and macroecological (i.e., large scale ecosystems) spatial scales (Noy-Meir, 1973; Parmesan et al., 2000). During drought conditions, limited water availability causes a decrease in plant biomass that affects the movements, reproduction, and overall behaviour of herbivores (Noy-Meir, 1974; Parmesan et al., 2000). Many animals adapt to drought conditions through behaviour modification (i.e., prolonged time spent sheltering in burrows) or migration to areas less affected by drought or with greater resource availability (Barrows, 2011; Noy-Meir, 1974; Parmesan et al., 2000). Generally, tortoises opt for the former. There are several studies documenting tortoise behaviour during times of decreased precipitation and food availability (Barrows, 2011; Bulova, 2002; Duda et al., 1999; Peterson, 1996). Most of these studies document decreased movements and increased time in burrows in an attempt to conserve resources until conditions improve (Duda et al., 1999; Freilich et al., 2000); however, some report little behavioural change (Rautenstrauch et al., 2002). Our study encompassed periods of both increased and decreased plant productivity and precipitation, including severe drought.

The burrowing characteristics of $G$. agassizii have been studied extensively in the Mojave Desert (e.g., Burge, 1978; Duda et al., 2002; Germano et al., 1994; Luckenbach, 1982). However, very little is published on the burrow use patterns of $G$. agassizii in the Sonoran Desert of California (Agha et al., 2015a; Agha et al., 2015b; Agha et al., 2017; Lovich \& Daniels, 2000). Populations of $G$. agassizii occur in and around the Orocopia and Cottonwood Mountains in the western Sonoran Desert of California (Berry \& Murphy, 2019; Dimmitt, 1977; Luckenbach, 1982). We examined burrow location and use, of radio-telemetered G. agassizii at two study sites between these mountains from 2015-2018. We also describe the burrows used by tortoises at both sites during the cold season inactivity or brumation period. These burrows are referred to as brumacula. We hypothesised that 1) burrow use would be similar between both sites because of their proximity, despite topographic differences, and 2) that tortoises would use fewer burrows during drought years of decreased precipitation and plant productivity because of their need to conserve water resources by decreasing activity levels and remaining in burrows until conditions improve.

\section{METHODS}

Study Sites

Data were collected from two study sites (Fig. 1) on 
opposing sides of the valley between the Cottonwood and Orocopia Mountains in the Sonoran Desert of southern California. Two major xeroriparian washes drain the valley: Maniobra Wash and Shavers Wash. The study sites are separated by Interstate 10 (a heavily trafficked multi-lane highway extending west to east from Santa Monica, California to Jacksonville, Florida). The Orocopia study site is located on the south side of Interstate 10 approximately $4-5 \mathrm{~km}$ south-east of the Cottonwood study site. The highway and distance between sites effectively isolate the two populations from the possibility of intermingling. The Cottonwood study site (north of Interstate 10) extends over an area of approximately $5.75 \mathrm{~km}^{2}$ in the southern part of Joshua Tree National Park (JTNP) in the area drained by Cottonwood Wash (a tributary of Shavers Wash). This site abuts the southern side of the Cottonwood Mountains and ranges in elevation from about $520 \mathrm{~m}$ AMSL on the bajada to over $800 \mathrm{~m} \mathrm{AMSL}$ in the rocky, mountainous slopes. Topography varies from gentle, sloping, sandy, bajadas with washes, to steep, bouldercovered terrain on the mountain slopes where the washes originate. The geology is dominated by granitic boulders and outcrops in the Cottonwood Mountains. Typical vegetation throughout is creosote scrub (Larrea tridentata) interspersed with brittlebush (Encelia farinosa), smoketrees (Psorothamnus spinosus), ironwoods (Olneya tesota), blue palo verde (Parkinsonia florida), and ocotillo (Fouquieria splendens). Additional site information is presented in Lovich et al. (2018b).

The Orocopia study site covers approximately $21 \mathrm{~km}^{2}$, from near the south side of Interstate 10 to the northern edge of the Orocopia Mountains, just west-south-west of Chiriaco Summit, a minimum of about 2-3 km away. The site is relatively flat, with a gentle uphill grade to the east and south towards the Orocopia Mountains. Elevations range from 482 to $618 \mathrm{~m}$ AMSL. This site is characterised by areas of desert pavement interrupted by sandy to gravelly soil with tank and jeep track scars from WWII training activities at nearby Camp Young in the early 1940s (Henley, 2000; Lathrop, 1983; Prose, 1985). There are a few scattered, small hills and many variably sized washes flowing northerly throughout the site, exposing occasional caliche layers. Orocopia schist is the dominant geology with relatively few granitic boulders in comparison with the Cottonwood site. The vegetation is dominated by creosote scrub (Larrea tridentata) interspersed with brittlebush (Encelia farinosa), burrobush (Ambrosia dumosa), and widely scattered ocotillo (Fouquieria splendens) and blue palo verde (Parkinsonia florida).

\section{Climate}

Southern and central California experienced the worst drought in as long as 1,200 years from 2012-2014 (Diaz \& Wahl, 2015; Griffin \& Anchukaitis, 2014). Even though the drought continued into 2016 (Flint et al., 2018), the effects were less devastating and allowed enough precipitation to fall for adequate germination of annual food plants for tortoises in 2015 and 2016 at the Cottonwood site due to spatial variation in rainfall. The year 2017 at the Orocopia site also proved to be a reasonably productive year for germination. However, conditions in the 2018 field season returned to severe drought, as a result of the extremely dry winter of 20172018 with only one small rainfall event in December. We used the Westmap (https://cefa.dri.edu/Westmap/) pixel function to calculate estimated mean annual precipitation. Estimated mean annual water year (WY) precipitation at the Cottonwood site was $7.84 \mathrm{~cm}$ in 2015 and $9.88 \mathrm{~cm}$ in 2016 . The estimated mean annual precipitation at the Orocopia site was $13.15 \mathrm{~cm}$ in WY2017 compared to $1.39 \mathrm{~cm}$ in WY2018. No germination of winter annual tortoise food plants was observed at the site in 2018. Long-term precipitation data for the Mojave and Sonoran Desert regions are summarised by Hereford et al. (2006) and Woodhouse (1997), respectively.

\section{Data Collection}

At the Cottonwood site, from March 2015 to July 2016, we walked line transects with 2-4 people spaced approximately 12-25 m apart as described in Lovich et al. (2014) looking for all evidence of tortoises and their burrows. Similar techniques were employed the Orocopia site from February 2017 to August 2018. As tortoises were located throughout the study site, adult males and females were outfitted with radio transmitters (models R1850, R1860; Advanced Telemetry Systems, and model HLPR 2850; Wildlife Materials radio) that weighed no more than $45 \mathrm{~g}$. Radios were attached following the procedures outlined in Boarman et al. (1998). All radiotelemetered tortoises were tracked approximately every 14 days during the egg production season from April to July and females were X-radiographed to determine clutch size for another study. After the egg production season, tortoises were tracked once monthly for the remainder of the year while transmitters were still attached (tortoises generally were not handled unless they were out of their burrows or easily accessible). While it is not completely known if G. agassizii burrow fidelity is negatively affected by human handling interactions at the burrow, Kahn et al. (2007) did not find a difference in the number of burrows used by or in home range size of gopher tortoises (Gopherus polyphemus) that were handled versus tortoises that were not handled. We did not observe any obvious changes to behaviour associated with tortoise handling. As tortoises were radio-tracked, we noted their position and activity in or near the burrow, and the number of tortoises occupying the burrow. Only radio-tracked tortoises were included in the burrow use study because those tortoises were each located up to 30 times (Table 1). Rautenstrauch et al. (2002) suggested that 50 or more locations per tortoise were needed to eliminate the bias of study duration time, but we did not have that many locations for any tortoise. To offset this potential bias, we utilised a weighted estimate of unique burrows used per tortoise per time interval. We define a "unique burrow" as a burrow that is identified belonging to the tortoise(s) that inhabited it. Since individual tortoises were monitored 
Table 1. Number of unique burrows used per tortoise at each study site during the entire radio-telemetered period. The identification number (ID) is the unique identifier for individual tortoises. Since the number of days is different for each tortoise due to later additions to the study and radio failures, a weighted estimate of burrow use was calculated. We calculated the number of unique burrows used for each individual tortoise every 30 days by dividing the total number of unique burrows used by the total number of days each tortoise was radio-transmittered, then multiplied that number by 30 days. The number of unique burrows reused is the number of burrows each tortoise used repeatedly non-consecutively.

\begin{tabular}{|c|c|c|c|c|c|c|c|}
\hline Site & ID & Sex & $\begin{array}{c}\text { Total \# times } \\
\text { located }\end{array}$ & $\begin{array}{l}\text { Total \# unique } \\
\text { burrows used }\end{array}$ & $\begin{array}{c}\text { Total \# days } \\
\text { radio-telemetered }\end{array}$ & $\begin{array}{c}\text { Unique burrows/ } \\
\mathbf{3 0} \text { days }\end{array}$ & $\begin{array}{c}\text { Total \# unique } \\
\text { burrows reused }\end{array}$ \\
\hline Cottonwood & 1 & $M$ & 27 & 14 & 469 & 0.896 & 0 \\
\hline Cottonwood & 2 & $\mathrm{~F}$ & 29 & 12 & 469 & 0.768 & 3 \\
\hline Cottonwood & 3 & $\mathrm{~F}$ & 11 & 7 & 469 & 0.448 & 1 \\
\hline Cottonwood & 7 & $\mathrm{~F}$ & 25 & 9 & 456 & 0.592 & 1 \\
\hline Cottonwood & 8 & $M$ & 24 & 9 & 456 & 0.592 & 1 \\
\hline Cottonwood & 9 & $\mathrm{~F}$ & 11 & 3 & 100 & 0.9 & 1 \\
\hline Cottonwood & 10 & $M$ & 10 & 4 & 133 & 0.902 & 1 \\
\hline Cottonwood & 11 & $\mathrm{~F}$ & 25 & 8 & 454 & 0.529 & 3 \\
\hline Cottonwood & 12 & $\mathrm{~F}$ & 27 & 11 & 452 & 0.73 & 4 \\
\hline Cottonwood & 13 & $M$ & 25 & 12 & 452 & 0.796 & 3 \\
\hline Cottonwood & 28 & $\mathrm{~F}$ & 7 & 5 & 97 & 1.546 & 0 \\
\hline Cottonwood & 31 & $\mathrm{~F}$ & 6 & 4 & 81 & 1.481 & 0 \\
\hline Orocopia & 33 & M & 30 & 7 & 489 & 0.429 & 3 \\
\hline Orocopia & 34 & $\mathrm{~F}$ & 28 & 11 & 509 & 0.648 & 2 \\
\hline Orocopia & 35 & $M$ & 28 & 8 & 476 & 0.504 & 2 \\
\hline Orocopia & 37 & $M$ & 24 & 7 & 449 & 0.468 & 2 \\
\hline Orocopia & 39 & $M$ & 24 & 7 & 448 & 0.469 & 2 \\
\hline Orocopia & 40 & $F$ & 28 & 9 & 531 & 0.508 & 2 \\
\hline Orocopia & 43 & $M$ & 20 & 5 & 407 & 0.369 & 1 \\
\hline Orocopia & 45 & $\mathrm{~F}$ & 26 & 9 & 428 & 0.631 & 1 \\
\hline Orocopia & 51 & $\mathrm{~F}$ & 15 & 3 & 263 & 0.342 & 1 \\
\hline
\end{tabular}

Table 2. Mean number of burrows used throughout the range of G. agassizii. Tortoises at the Orocopia and Cottonwood study sites used a similar number of burrows when compared to G. agassizii at other sites. The term "burrows" refers to all categories of burrow substrate. Mean burrows is the number of burrows that tortoises used during the time frame specified. Time is the time frame as indicated in each study. Time frame is variable for each study listed as there is little consistency amongst publications. It is assumed that only burrows found housing a tortoise were used since authors did not specify otherwise. Burrows were only counted once each season regardless of the number of times a tortoise(s) repeatedly used a burrow and then counted once again the next season if they were used, unless specified otherwise below.

\begin{tabular}{|c|c|c|c|c|}
\hline Citation & Location & $\bar{\chi}$ Burrows & Time & Additional Notes \\
\hline Our site $_{a}$ & Orocopia site & $8.3 ; 9.1$ & 365 Days & $\begin{array}{l}\text { February-December 2017; January-Au- } \\
\text { gust 2018, Estimated potential mean }\end{array}$ \\
\hline Our site $_{a}$ & Cottonwood site & $7.5 ; 12.5$ & 365 Days & $\begin{array}{l}\text { March-December 2015; January-July } \\
\text { 2016, Estimated potential mean }\end{array}$ \\
\hline Rautenstrauch et al. (2002) & $\begin{array}{l}\text { Mojave Desert of } \\
\text { Nevada }\end{array}$ & 11.7 & Year & $\begin{array}{l}\text { Over all years (January 1992-February } \\
\text { 1995) }\end{array}$ \\
\hline Freilich et al. $(2000)_{b}$ & $\begin{array}{l}\text { Mojave Desert of } \\
\text { California }\end{array}$ & $\begin{array}{l}5.6 ; 7.9 \\
12.6 ; 3.8\end{array}$ & $\begin{array}{l}\text { Year (tortoise activ- } \\
\text { ity season) }\end{array}$ & $\begin{array}{c}\text { Each year respectively (April 1993-May } \\
\text { 1996), a year was considered the tor- } \\
\text { toise activity season of March or April } \\
\text { until May (1994 \& } 1996 \text { were drought } \\
\text { years) }\end{array}$ \\
\hline Duda et al. (1999) & $\begin{array}{l}\text { Mojave Desert of } \\
\text { California-(MCAGCC) }\end{array}$ & $\begin{array}{l}6.9 / 6.2 \\
3.8 / 3.1\end{array}$ & Year & $\begin{array}{c}\text { Male/female respectively per year. } \\
\text { March-December 1995; March-Novem- } \\
\text { ber } 1996 \text { (drought year), Marine Corps } \\
\text { Air Ground Combat Center }\end{array}$ \\
\hline Duda et al. (1999) & $\begin{array}{l}\text { Mojave Desert of } \\
\text { California-(JTNP) }\end{array}$ & $\begin{array}{l}\text { 13.8/11.6; } \\
4.8 / 4.4\end{array}$ & Year & $\begin{array}{l}\text { Male/Female respectively per year. } \\
\text { March-December } 1995 \text { \& } 1996 \text { (drought } \\
\text { year), Joshua Tree National Park }\end{array}$ \\
\hline
\end{tabular}


for differing time periods from when they were first and last outfitted with radio transmitters, we calculated the weighted estimate of burrow use as the number of unique burrows used by an individual tortoise divided by the total number of days each tortoise was radiotransmittered. We then multiplied that number by 30 or 365 to generate an estimate of the number of individual burrows used per 30 (Table 1) or 365 days (Table 2), respectively. The Spearman correlation coefficient was used to measure the strength of association between the number of burrows tortoises used with the number of days each tortoise was monitored since monitoring duration in days was not normally distributed. The yearly (365 days) calculation was only used as a comparison with other studies and represents the potential number of burrows that each tortoise is capable of using every year.

At both sites, some burrows were re-occupied by the same or different tortoises throughout the year. For the count of unique burrows, each burrow was counted one time each calendar year even though the tortoise may have used that burrow two calendar years in a row (i.e., if a tortoise used a burrow repeatedly for two consecutive calendar years, it was counted as a unique burrow used once each year). Each year was analysed separately due to the dramatic difference in precipitation amongst years. Tortoises at both sites reused burrows, defined as the repetitive non-consecutive use of a burrow by an individual (e.g., a tortoise used a unique burrow, left for another burrow(s), and then returned to the first burrow one or more times). Since we were not locating tortoises on a daily basis, we made the assumption that tortoises located in the same burrow on consecutive trips, remained in that burrow in between detections. We compared and contrasted our data with other published data. While our burrows are all considered to be unique to the tortoise that inhabits them, other authors do not specify this criterion, and instead may count the total number of times tortoises were found in burrows, potentially counting a unique burrow multiple times; this is noted as appropriate in our comparisons (Table 2).

All burrows used in this study were given an individual identification number, marked with an aluminum tag, and a GPS point was taken using a Garmin Oregon 550T GPS unit (accurate to +/- $3 \mathrm{~m}$ ). Only burrows that were observed to be occupied by radio telemetered tortoises were included in our analyses. Descriptions of each burrow were recorded, including the general burrow location relative to obvious landmarks and burrow type. Burrow type was not always recorded at every burrow at the Cottonwood site since the protocol for recording burrow type was established after the Cottonwood study had begun for other reasons (e.g., collecting demographic and reproductive data). Burrow type was classified into three categories: soil burrow, pallet, or rock shelter. We define a soil burrow as a burrow that is excavated in a mostly soil substrate and that is as long or longer than a tortoise's shell length. A pallet is a shallow indentation, often under the canopy of a shrub where a tortoise can be partially or completely concealed. A rock shelter is an opening in or under one or more rocks that form a "cave". We use the term "burrow" loosely to represent all shelter types in this manuscript for simplification unless noted otherwise. Burrow mouth orientation was noted at the Orocopia site for each burrow but not always noted at the Cottonwood site for the reason given above. Therefore, landscape aspect, slope, and elevation were determined for each burrow location through geospatial analysis (ARCGIS 10.5.1) at both sites for consistency. A 10-metre digital elevation model obtained from the National Map (U.S. Geological Survey: https://www.usgs. gov/core-science-systems/national-geospatial-program/ national-map) was first used to create aspect and slope raster layers prior to extracting terrain values at each burrow location. Each burrow in the geospatial analysis was only included once, even though the burrow may have been used by a tortoise or tortoises many times. We ran a Watson-Williams F-Test for circular statistics to compare the landscape aspect vectors determined from the geospatial analysis.

Brumation events, the ectotherm analogue of hibernation, were monitored from the end of the spring/ summer activity season until the beginning of the following spring activity season. The brumation entrance date was the date tortoises discontinued moving from one burrow to another and remained in one burrow until the month they were located either out of their burrow or in a new burrow in the late winter or spring season of the following calendar year (i.e., brumation emergence date; with one exception for a tortoise that changed burrows in the winter). We hand-measured brumaculum depth whereas aspect was determined through geospatial analysis (ARCGIS 10.5.1). Brumaculum depth was measured from the entrance of the burrow to the farthest point reached with a flexible tape measure to the back of the burrow. The tape measure was not always able to reach the very end of some burrows due to burrow curves and side tunnels, so measurements represent a minimum depth. Because the study duration was less than two full years at each site, we collected one complete season of winter dormancy data for brumacula use at each.

\section{RESULTS}

\section{Burrow Use}

Relocations of radioed tortoises ranged from 6-30 events over both studies (Table 1). At the Cottonwood site, tortoises used a range of 3-14 unique burrows each during the 16-month study, and tortoises at the Orocopia site occupied a range of 3-11 unique burrows each during the 19-month study (Table 1) for a total of 164 unique burrows for all tortoises across both sites. Tortoises at the Orocopia site used an estimated mean of 0.485 unique burrows per 30 days over the study duration (Table 1 ). Estimated potential mean number of burrows used at the Orocopia site per 365 days was 8.3 in 2017 and 9.1 in 2018 (Table 2). Tortoises at the Cottonwood site used an estimated mean of 0.848 unique burrows per 30 days over the study duration and an estimated potential 
mean number of burrows per 365 days of 7.5 in 2015 and 12.5 in 2016 (Tables 1; 2). The Orocopia tortoises utilised 61 soil burrows, 3 pallets, and 2 rock shelters. The burrows used by the Cottonwood tortoises included 27 soil burrows, 1 pallet, and 28 rock shelters. The number of unique burrows occupied by tortoises throughout our study at both sites combined increased with the number of days that individual tortoises were monitored (Fig. 2). Monitoring duration explained $70 \%$ of the variation in number of unique burrows occupied. At the Orocopia site, the median estimated number of unique burrows used per tortoise per 30 days did not differ between the non-drought $(\tilde{x}=0.7)$ and drought-affected years $(\tilde{x}=0.7)$ of 2017 and 2018 (Mann-Whitney U Test Statistic = 33.0, $P=0.5$, Chi-Square approximation $=0.4, \mathrm{df}=1$ ).

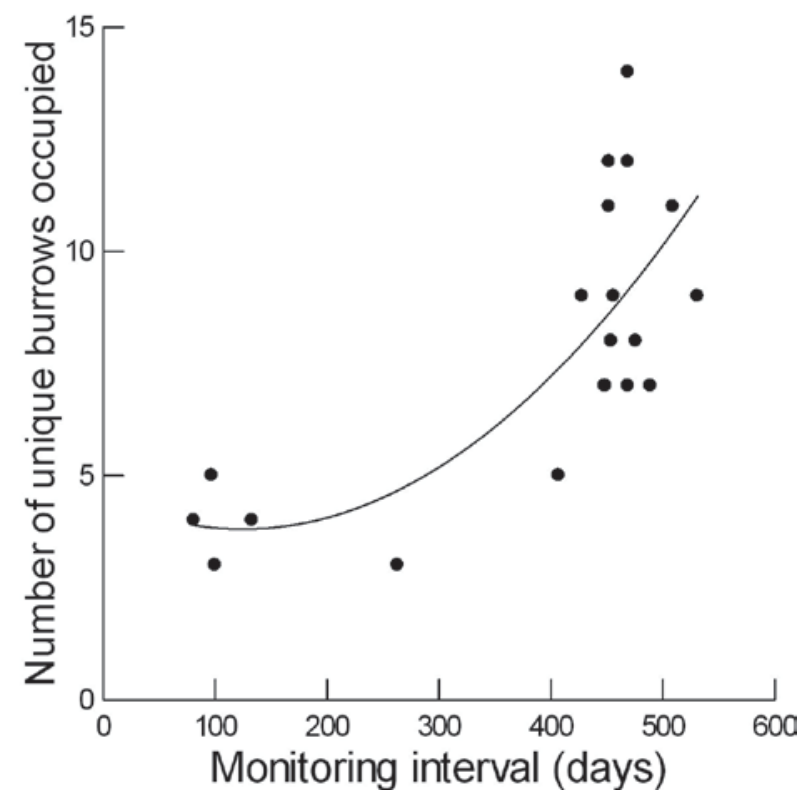

Figure 2. The number of unique burrows used by each tortoise within the radio-telemetered monitoring period. A quadratic smoother has been applied to demonstrate that the increase in the number of burrows occupied is directly proportional to the number of days that tortoises are radiotelemetered. A quadratic smoother appears to fit the data well. Burrow occupancy increases with time.

\section{Topography}

Overall, mean burrow landscape aspect vectors between sites were statistically different (Watson-Williams F-Tests, $\mathrm{F}=222.4^{\circ}, \mathrm{df}=1,147^{\circ}, \mathrm{p}<0.001$ ) based on our geospatial analyses. The topography at the Orocopia site had a predominately northerly aspect while the Cottonwood site had a south-westerly aspect, and that was reflected in the aspects of burrow locations (Orocopia mean aspect vector $=356.8^{\circ} \pm \mathrm{SD} 22.7^{\circ}, \mathrm{n}=65$; Cottonwood mean aspect vector $=231.1^{\circ} \pm$ SD $63.5^{\circ}, n=84$; Fig. 3). Burrows at the Cottonwood site ranged from $588 \mathrm{~m}-762$ $\mathrm{m}$ AMSL in elevation $(=663.7 \mathrm{~m}, \mathrm{SD}=49.0)$ and a slope range of $1.9 \%-33.4 \%(=10.7 \%$, SD = 10.6). Tortoise burrows at the Orocopia site ranged in elevation from $502 \mathrm{~m}-574 \mathrm{~m}$ AMSL (= $537.6 \mathrm{~m}, \mathrm{SD}=16.2)$ with a slope range of $0.6 \%-2.4 \%(=1.6 \%, S D=0.4)$.

\section{Burrow Reuse}

Each tortoise at the Orocopia site reused previously inhabited burrows, whereas, some tortoises at the Cottonwood site did not (Table 1). The number of burrows reused by tortoises increased with the number of days since radios were attached. For Cottonwood, the Pearson correlation coefficient between those two variables was $0.53(P=0.08)$. The value for Orocopia was $0.67(P=0.05)$. For both sites combined the value was $0.55(\mathrm{P}=0.009)$. At the Orocopia site, some tortoises also showed increased burrow fidelity for extended periods of time. Female tortoise \#51 was located in only three burrows during the 263-day tracking period including one burrow that was used for 10 months straight (from brumation into the following summer). Male tortoise \#43 was only located in five burrows during the 407 days he was tracked. The burrow where he was most often located was used for eight months leading up to and during brumation (two of those months were during the summer season).

\section{Cohabitation}

Tortoises at both sites used burrows that appeared to be inhabited only by that individual, but on several occasions, tortoises used burrows that originally sheltered a different tortoise. For example, at the Orocopia site, a burrow was originally found sheltering male \#35. Thereafter, male \#33 was found twice in that burrow, as well as female \#40 who was also found twice in that same burrow (cohabitating each time with either male \#35 or male \#33). All the cohabitation events that occurred over both sites ( $n=7$ ) involved male/female combinations, and five of these events occurred after the egg production season for the region (Lovich et al., 2018b) (April-June) between the months of August and October, while two events occurred in April. At the Orocopia site, a total of six cohabitation events were recorded. One event in October involved three tortoises simultaneously using a burrow (two males [\#39 \& \#50] and one female [\#51]). At the Cottonwood site, there was only one possible cohabitation event where a marked male tortoise was sitting on the apron of a radio-telemetered female tortoises burrow while she was inside. Although we never saw the male tortoise in the burrow, he could have been in the burrow before or after our observation.

\section{Brumation}

Seven tortoises were included in the brumation data at the Cottonwood site. Four radio-telemetered tortoises at the Cottonwood site were not included in the brumation study either because they were not located prior to the brumation period or they had a radio failure prior to the beginning of the brumation period. Eightysix percent $(n=6)$ of the tortoises at the Cottonwood site entered brumation in November of 2015, and the earliest brumation entrance date was October 2015 by one female (\#11) (Table 3). Eighty-six percent $(n=6)$ of the tortoises also exited brumation in February 2016. The same female tortoise (\#11) that entered brumation earlier than all other tortoises emerged in March 2016, later than all other tortoises. Nine tortoises were included 
Table 3. Brumacula data for both the Orocopia and Cottonwood study sites. ID is the individual tortoise identification number assigned to each tortoise. Depth is the length of the burrow from the mouth to the farthest point reached with the tape measure at the back of the burrow. One tortoise at the Orocopia site used two burrows during one brumation season creating an extra burrow for the Orocopia data. Some radio-telemetered tortoises included in the overall burrow study were not located prior to the brumacula study, accounting for the decreased number of tortoises included in this list. We were unable to collect burrow depth on tortoises \#2 and \#8 due to burrow collapse.

\begin{tabular}{|c|c|c|c|c|c|c|}
\hline Site & ID & Sex & Month/Year of Brumation Duration & $\begin{array}{c}\text { Depth } \\
(\mathrm{cm})\end{array}$ & $\begin{array}{c}\text { Mouth Orientation } \\
\text { (degrees) }\end{array}$ & $\begin{array}{c}\text { Landscape Aspect } \\
\text { (degrees) }\end{array}$ \\
\hline Cottonwood & 1 & $\mathrm{M}$ & November 2015-February 2016 & 117 & 170 & 236 \\
\hline Cottonwood & 2 & $\mathrm{~F}$ & November 2015-February 2016 & & 180 & 246 \\
\hline Cottonwood & 7 & $\mathrm{~F}$ & November 2015-February 2016 & 35 & 80 & 152 \\
\hline Cottonwood & 8 & M & November 2015-February 2016 & & 224 & 179 \\
\hline Cottonwood & 11 & $\mathrm{~F}$ & October 2015-March 2016 & 100 & 140 & 236 \\
\hline Cottonwood & 12 & $\mathrm{~F}$ & November 2015-February 2016 & 90 & 280 & 322 \\
\hline Cottonwood & 13 & $\mathrm{M}$ & November 2015-February 2016 & 84 & 274 & 320 \\
\hline Orocopia & 33 & $\mathrm{M}$ & November 2017-March 2018 & 100 & 55 & 37 \\
\hline Orocopia & 34 & $\mathrm{~F}$ & September 2017-February2018 & 96 & 230 & 6 \\
\hline Orocopia & 35 & M & November 2017-March 2018 & 56 & 220 & 41 \\
\hline Orocopia & 37 & M & November 2017-March 2018 & 107 & 340 & 53 \\
\hline Orocopia & 39 & M & November 2017-March 2018 & 48 & 90 & 0.9 \\
\hline Orocopia & 40 & $\mathrm{~F}$ & November 2017-May 2018 & 62 & 250 & 347 \\
\hline Orocopia & 43 & M & October 2017-March 2018 & 87 & 160 & 253 \\
\hline \multirow[t]{2}{*}{ Orocopia } & 45 & $\mathrm{~F}$ & November 2017-January 2018 & 140 & 300 & 335 \\
\hline & & & January 2018-April 2018 & 53 & 155 & 337 \\
\hline Orocopia & 51 & $\mathrm{~F}$ & November 2017-May 2018 & 120 & 270 & 323 \\
\hline
\end{tabular}

in the Orocopia brumation study. Seventy-eight percent of the tortoises $(n=7)$ entered brumation in November 2017 and fifty-six percent $(n=5)$ emerged in March 2018 (Table 3). All males entered brumation between October $(n=1)$ and November $(n=4)$ in 2017 and emerged in March 2018. Of the four radio-telemetered female tortoises at the Orocopia site, three entered brumation in November 2017 and emerged in April and May of 2018 (Table 3). The fourth female (\#34) went into her brumaculum early in September 2017, and she was also the earliest to emerge in February 2018. We do know that females \#34 and \#40 emerged between February and March the previous year in 2017, since female tortoise \#34 was originally found basking on 16 February 2017 and female \#40 was discovered courting with male \#35 on 15 March 2017. At the Orocopia site, one female (\#45) used two brumation burrows in a single brumation period. She entered her first brumaculum in November 2017, was found in her second brumaculum in January 2018, and finally emerged from brumation in April 2018 (Table 3). These were both considered brumacula due to the seasonal timing.

At Cottonwood, brumacula mouth orientation ranged from 80-280 degrees, with a general southerly preference for all tortoises (Fig. 4; Table 3). Fifty-seven percent $(n=4)$ of the brumacula were soil burrows while the remainder $(n=3)$ were rock shelters. Brumacula at the Orocopia site had a burrow mouth orientation ranging from 55-340 degrees, with the greatest number of brumacula mouth openings ( $n=5$ ) facing south-westerly (Fig. 4; Table 3).
Eight of ten brumacula were in soil burrows (one was in a caliche layer); the two remaining burrows were a pallet and a rock shelter. Burrows used for brumation at both sites tended to have southerly mean burrow mouth opening orientation vectors ( \pm circular SD; Fig. 4) but sample sizes were too small for further statistical comparison (Cottonwood mean vector $=196.0^{\circ} \pm 72.0^{\circ}, \mathrm{n}$ = 7; Orocopia mean vector $=231.2^{\circ} \pm 95.0^{\circ}, \mathrm{n}=10$ ). Mean depth of brumacula were as follows: Orocopia: $86.9 \mathrm{~cm}$, range 48-140 cm; Cottonwood: $85.2 \mathrm{~cm}$, range 35-177 cm (Table 3).

\section{DISCUSSION}

\section{Burrow Use and Selection}

In this study, we documented different aspects of the burrowing habits (including brumation and cohabitation) of two proximate but separate populations of $G$. agassizii in the Sonoran Desert of California and how they use the geologicand topographicterrain within their home ranges during varied periods of precipitation. After analysis of the data, our initial two hypotheses were rejected. First, while tortoises used similar substrates in which to construct burrows, burrow types were different as a result of site-specific geologic and topographic characteristics. Second, tortoises did not use fewer burrows during a year of greatly decreased precipitation and plant productivity as expected. Previous research suggests that G. agassizii actively select burrow and shelter sites based on certain environmental characteristics (Duda et al., 2002; Lovich 
\& Daniels, 2000; Sah et al., 2016). Tortoises at both sites utilised rock shelters, soil burrows, and/or pallets at one time or another and used new burrows as well as previously used burrows, and over a range of elevational relief.

Traditionally, Agassiz's desert tortoises (G. agassizii) have been characterised as occupants of desert flats, while its congener, Morafka's desert tortoises ( $G$. morafkai) prefers rocky, mountainous terrain (Germano et al., 1994). However, previous studies reveal reciprocal use of habitats by both species depending on habitat availability and tortoise preference (Averill-Murray \& Averill-Murray, 2005; Bury et al., 1994; Germano et al., 1994). Several of the tortoises at Cottonwood exhibited shelter site use comparable to G. morafkai in Arizona (Germano et al., 1994; Riedle et al., 2008). Tortoises at Cottonwood often used granitic boulder rock shelters on hillsides (when a rocky hill slope was available within the tortoise's home range), whereas some utilised soil burrows on the nearby flat topography, and several tortoises utilised both forms of burrows within their home range. At the Orocopia site, we located most of the tortoises and burrows on the flats and in washes, possibly due to the rarity of steep boulder-strewn terrain in the area. Burrow use at the Orocopia site is consistent with other reports of $G$. agassizii behaviour in the Mojave Desert of California (Berry et al., 2002; Ernst \& Lovich, 2009; Murphy et al., 2011).

The locations of burrows at both sites tended to match the overall aspect of the landscape. For example, on the north-facing Orocopia landscape there were topographic features (washes and small hills) with aspects facing other directions but most burrows were located on north-facing aspects (Fig. 3), even though tortoises had the option to select otherwise. Alternatively, Cottonwood tortoises utilised burrows primarily located on a southwesterly landscape aspect, which was also the overall aspect of the landscape. Other studies identify landscape aspects which tortoises tend to utilise most (Anderson et al., 2000; Bulova, 1994), however, they do not state the overall landscape aspect of the study site as a comparison.

\section{Burrow Reuse}

Tortoises demonstrate a preference for certain burrows, returning to these burrows for subsequent "reuse", possibly as a means of energy conservation. It is energetically less expensive to reuse a previous burrow than to dig a new one. Other studies show that tortoises have varying levels of burrow fidelity. Burge (1978) reported that $73 \%$ of tortoises used a burrow for 2-15 days and $19 \%$ for 16-46 days, while Duda et al. (1999) noted three tortoises did not move from their burrows for the entirety of a single season during a drought year. At the Orocopia site, all tortoises reused either one or two burrows during the study period. Our results indicate that, generally, the detection of burrow reuse increases with time tortoises are monitored. Due to the intermittent observation of tortoises, it is assumed that they may reuse burrows more frequently

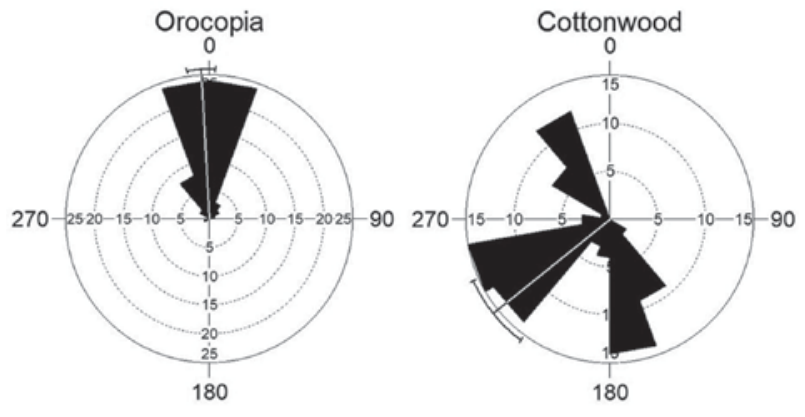

Figure 3. Site aspect orientation roses based on data determined through geospatial analysis (ARCGIS 10.5.1). The mean vector is shown with the associated $95 \%$ confidence interval. Orocopia tortoises utilised landscapes with north-facing aspects and Cottonwood tortoises primarily utilised landscapes with south-western facing aspects overall throughout radio-telemetered periods. Burrows at both sites tended to orientate in conformance with the landscape aspects created by topography.

than documented (Burge, 1978). At Cottonwood, three tortoises did not reuse any burrow during the study. Two of the afore-mentioned three tortoises were radiotransmittered for the shortest duration of time (81 and 97 days), which may account for the lack of subsequent observed burrow use. However, the third tortoise (male \#1) was the first marked tortoise on the site and had the longest radio-telemetered duration (469 days) (Table 1 ). One tortoise (\#12) reused four different burrows during 452 days at the Cottonwood site, which is the greatest number of burrows reused at either site. In a previous study on the northern side of the Cottonwood mountains, in the Pinto basin, tortoises were noted reusing previous burrows consistently, only adding new burrows occasionally (Freilich et al., 2000).

\section{Cohabitation}

Tortoise cohabitation is documented in the wild; however, they are more often found individually in burrows (Bulova, 1996; Burge, 1978). Woodbury \& Hardy (1948) noted that although tortoises have small home ranges, they often overlap with the home ranges of other tortoises, increasing the odds of cohabitation. Our study documents cohabitation during the spring as well as the summer and fall seasons and involving mostly opposite sex associations. We did not observe any cohabitations during the brumation period. Other studies have documented cohabitation events, especially during the reproductive season (Bulova, 1994; Burge, 1978). Woodbury \& Hardy (1948) discovered up to 17 tortoises in one burrow simultaneously during the brumation period and estimated an average cohabitance of 3.11 tortoises per burrow at a study site in Utah.

\section{Drought}

Tortoises can tolerate high concentrations of biological wastes and conserve water in urinary bladders in times of 
Table 4. Number of unique burrows used by radiotelemetered tortoises per 30 days during each individual year 2017 and 2018 at the Orocopia site only. The identification number (ID) is the unique identifier for individual tortoises. A mean of 0.7 burrows were used per 30 days each year. The drought year (2018) did not influence the number of burrows used.

\begin{tabular}{lccc}
\hline & & \multicolumn{2}{c}{ Unique Burrows/30 days } \\
\cline { 3 - 4 } ID & Sex & 2017 & 2018 \\
\hline 33 & $\mathrm{M}$ & 0.590 & 0.774 \\
34 & $\mathrm{~F}$ & 0.492 & 1.371 \\
35 & $\mathrm{M}$ & 0.616 & 0.774 \\
37 & $\mathrm{M}$ & 0.643 & 0.643 \\
39 & $\mathrm{M}$ & 0.753 & 0.643 \\
40 & $\mathrm{~F}$ & 0.755 & 0.536 \\
43 & $\mathrm{M}$ & 0.455 & 0.789 \\
45 & $\mathrm{~F}$ & 0.807 & 0.682 \\
51 & $\mathrm{~F}$ & 1.017 & 0.514 \\
\hline
\end{tabular}

drought (Nagy \& Medica, 1986; Peterson, 1996). Burrows provide a safe refuge and minimise physiologic water loss through underground moisture content (Bulova, 2002; Peterson, 1996). During drought years, tortoises can be very difficult to find, and high-density tortoise areas can appear to be largely deserted due to these water conservation mechanisms (Anderson et al., 2000; Freilich et al., 2000). We experienced this phenomenon during the 2018 drought year $(1.39 \mathrm{~cm}$ precipitation) since only one new tortoise was found and marked that year. The year 2017 provided good germination for tortoise annual food plants with the yearly precipitation total of 13.15 $\mathrm{cm}$. However, 2018 had no germination of winter annual plants. Surprisingly, the mean number of unique burrows used by tortoises per 30 days between 2017 and 2018 at the Orocopia site were identical ( 0.7 burrows) (Table 4). Similarly, Rautenstrauch et al. (2002) noted that tortoises at his study site did not demonstrate a change in burrow use (the number of burrows used and the amount of time tortoises spent in their burrows) during a period of decreased precipitation of $11.7 \mathrm{~cm}$ from the site average of $13.9 \mathrm{~cm}$ annually, even though two years of the five year study had above average precipitation of $26.9 \mathrm{~cm}$ and $26.6 \mathrm{~cm}$. They suggested that perhaps the precipitation decrease was not dramatic enough for a behavioural response. However, Duda et al. (1999) and Freilich et al. (2000) reported a significant decrease in the number of burrows tortoises used during drought $(1.2 \mathrm{~cm}$ winter precipitation and less than $5.5 \mathrm{~cm}$ yearly precipitation, respectively), increasing the amount of time spent in a particular burrow and decreasing home range size. With extended periods of time inactive in burrows and less time above ground, tortoises conserve energy by reducing their metabolic rates, allowing them to tolerate poor conditions for longer periods of time (Henen, 1997; Henen, 2002).

\section{Brumation}

We had one complete season of monitored data on
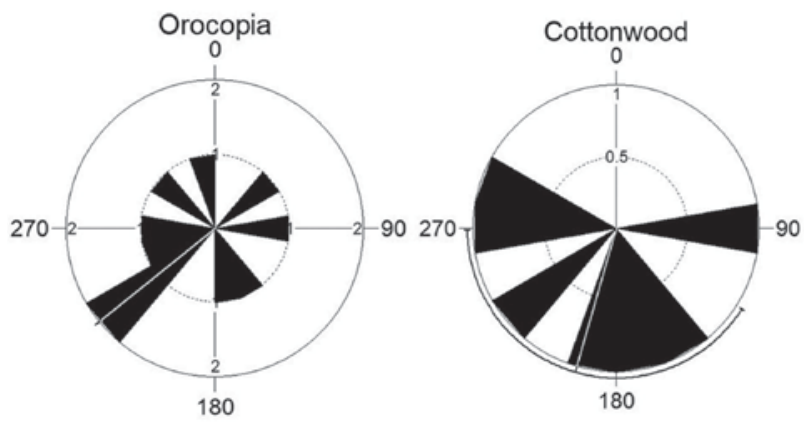

Figure 4. Orocopia (left) and Cottonwood (right) brumacula burrow mouth orientation roses. This dataset was hand-measured in the field with a compass, not with geospatial analysis software. The mean vector is shown with the associated $95 \%$ confidence interval. Tortoises predominantly favoured a south-western mean burrow mouth orientation vector for brumacula. There was no obvious relationship between the burrow mouth orientation vectors and topography aspect at the Orocopia site, whereas, at the Cottonwood site, burrow mouth openings tended to orientate in conformance with the general aspect of the landscape.

brumacula use at each site (Table 3). Our results are comparable to other brumation data reported. Most tortoises at other sites have been reported entering brumation between October - December and are reported exiting between February and, at the latest, June (Bailey et al., 1995; Burge, 1978; Nussear et al., 2007; Rautenstrauch et al., 1998). All tortoises at the Orocopia site exhibited later emergence in 2018 than tortoises at the Cottonwood site in 2016 overall (Table 3). Bailey et al. (1995) noted that female G. morafkai emerged earlier than males at two sites, but we did not observe this phenomenon at either of our sites. Females may remain in their burrows for extended periods of time in the spring during drought conditions to conserve resources for reproduction (Henen, 1997; Henen, 2002). Three of the four Orocopia female tortoises emerged from brumation later than all of the male tortoises, in April and May of 2018.

Warmer brumacula environments may provide thermal buffering, providing a physiologic benefit for reproduction (Averill-Murray et al., 2002a; Bailey et al., 1995). South-facing slopes tend to have increased soil temperatures and solar radiation with a decreased 24-hour temperature swing (Bailey et al., 1995; Nobel \& Linton, 1997; Warren, 2008) creating a consistently warmer brumaculum environment during the winter. At both of our sites, brumacula openings tended to orientate toward the south-west even though the general aspect of the Orocopia landscape is north and overall, most burrows (including brumacula) at the Orocopia site had a north facing landscape aspect (Table 3; Fig. 4). Tortoises at the Cottonwood site predominantly inhabited brumacula with southerly facing openings on southerly facing landscape aspects (Fig. 4). Bailey et 
al. (1995) noted that tortoises in the Sonoran Desert demonstrated a preference for southern facing slopes during two brumation seasons. Brumacula depth may also provide some thermal buffer. The deeper the burrow, the more consistent the ambient temperature is over a 24-hour period (Mack et al., 2015; Rosenberg et al., 1983), protecting tortoises from reaching their critical thermal minimum of $4.4{ }^{\circ} \mathrm{C}$ (Averill-Murray et al., 2002a; Lowe et al., 1971; Woodbury \& Hardy, 1948).

The information presented here demonstrates that G. agassizii utilise habitats differently depending on the availability of local resources within the geological and environmental constraints of their home ranges. Our study provides additional insight to the limited information for tortoise behaviours in association with burrowing habits of $G$. agassizii in the Sonoran Desert of California. Tortoise burrow use varies due to the interactions of precipitation, season, and landscape characteristics, compelling tortoises to adjust to climates and environmental landscapes, even over small spatial and temporal scales.

\section{ACKNOWLEDGEMENTS}

We thank Laura Tennant, Amanda Smith, Jenna Norris, Rachel Henderson, and Erin Cox for assisting with this project, as well as Al Muth and Chris Tracy at Boyd Deep Canyon Desert Research Center (doi:10.21973/N3V66D) for providing housing. Special thanks to Michael Vamstad for reviewing an earlier version of the manuscript. Research was supported by the Coachella Valley Conservation Commission and the California Department of Fish and Wildlife. Research was conducted under permits from the U.S. Fish and Wildlife Service, the Bureau of Land Management, the National Park Service, and the California Department of Fish and Wildlife. We are grateful to the Institutional Animal Care and Use Committee of Northern Arizona University for reviewing and approving our research procedures with tortoises. Any use of trade, product or firm names is for descriptive purposes only and does not imply endorsement by the U.S. Government.

\section{REFERENCES}

Agha, M., Augustine, B., Lovich, J.E., Delaney, D., Sinervo, B., Murphy, M.O., Ennen, J.R., Briggs, J.R., Cooper, R. \& Price, S.J. (2015a). Using motion-sensor camera technology to infer seasonal activity and thermal niche of the desert tortoise (Gopherusagassizii).JournalofThermalBiology49,119-126.

Agha, M., Delaney, D., Lovich, J.E., Briggs, J., Austin, M. \& Price, S.J. (2015b). Nelson's big horn sheep (Ovis canadensis nelsoni) trample Agassiz's desert tortoise (Gopherus agassizii) burrow at a California wind energy facility. Bulletin, Southern California Academy of Sciences 114, 5863.

Agha, M., Smith, A.L., Lovich, J.E., Delaney, D., Ennen, J.R., Briggs, J., Fleckenstein, L.J., Tennant, L.A., Puffer, S.R., Walde, A., Arundel, T.R., Price, S.J. \& Todd, B.T. (2017). Mammalian mesocarnivore visitation at tortoise burrows in a wind farm. The Journal of Wildlife Management 81, 1117-1124.
Anderson, D.R., Burnham, K.P., Lubow, B.C., Thomas, L., Corn, P.S., Medica, P.A. \& Marlow, R.W. (2000). Field trials of line transect methods applied to estimation of desert tortoise abundance. The Journal of Wildlife Management 65, 583597.

Averill-Murray, R., Martin, B., Bailey, S. \& Wirt, E. (2002a). Activity and behavior of the Sonoran desert tortoise in Arizona. In The Sonoran desert tortoise: natural history, biology, and conservation, 135-158. Van Devender, T.R. (ed.). Tucson, Az, USA: The University of Arizona Press.

Averill-Murray, R.C. \& Averill-Murray, A. (2005). Regional-scale estimation of density and habitat use of the desert tortoise (Gopherus agassizii) in Arizona. Journal of Herpetology 39, 65-72.

Averill-Murray, R.C., Woodman, A.P. \& Howland, J.M. (2002b). Population ecology of the Sonoran desert tortoise in Arizona. In The Sonoran desert tortoise: natural history, biology, and conservation, 109-134. Van Devender, T.R. (ed.). Tucson, Az, USA: The University of Arizona Press.

Bailey, S.J., Schwalbe, C.R. \& Lowe, C.H. (1995). Hibernaculum use by a population of desert tortoises (Gopherus agassizii) in the Sonoran Desert. Journal of Herpetology 29, 361-369.

Barrows, C. (2011). Sensitivity to climate change for two reptiles at the Mojave-Sonoran Desert interface. Journal of Arid Environments 75, 629-635.

Berry, K.C. \& Murphy, R.W. (2019). Gopherus agassizii (Cooper 1861) - Mojave desert tortoise, Agassiz's desert tortoise. In Chelonian Research Monographs. Conservation Biology of Freshwater Turtles and Tortoises: A Compilation Project of the IUCN/SSC Tortoise and Freshwater Turtle Specialist Group, 109.101-109.145. Rhodin, A.G.J., Iverson, J.B., van Dijk, P.P., Stanford, C.B., Goode, E.V., Buhlmann, K.A., Pritchard, P.C.H. \& Mittermeier, R.A. (Eds.). Chelonian Research Foundation and Turtle Conservancy.

Berry, K.H., Morafka, D.J. \& Murphy, R.W. (2002). Defining the desert tortoise(s): our first priority for a coherent conservation strategy. Chelonian Conservation and Biology 4, 249-262.

Boarman, W.I., Goodlett, T. \& Goodlett, G. (1998). Review of radio transmitter attachment techniques for chelonian research and recommendations for improvement. Herpetological Review 29, 26-33.

Bulova, S.J. (1994). Patterns of burrow use by desert tortoises: gender differences and seasonal trends. Herpetological Monographs 8, 133-143.

Bulova, S.J. (1996). Burrow use by desert tortoises (Gopherus agassizii): social factors. Proceedings of the Desert Tortoise Council Symposium 1993, 23-25.

Bulova, S.J. (2002). How temperature, humidity, and burrow selection affect evaporative water loss in desert tortoises. Journal of Thermal Biology 27, 175-189.

Burge, B. (1978). Physical characteristics and patterns of utilization of cover sites used by Gopherus agassizii in southern Nevada. Proceedings of the Desert Tortoise Council Symposium 1978, 80-111.

Bury, R.B., Esque, T., DeFalco, L. \& Medica, P. (1994). Distribution, habitat use and protection of desert tortoise in the Eastern Mojave Desert. Fish and Wildlife Research 13, 57-72.

Crowe, D.E. \& Longshore, K.M. (2013). Nest site characteristics and nesting success of the western burrowing owl in the eastern Mojave Desert. Journal of Arid Environments 94, 113-120. 
Currylow, A., Walde, A.D. \& Walde, A.M. (2016). Gopherus agassizii (Mojave desert tortoise) and Coluber flagellum piceus (red racer). Burrow associates. In Natural History Notes, 122-123. Herpetological Review 47.

Diaz, H.F. \& Wahl, E.R. (2015). Recent California water year precipitation deficits: A 440-year perspective. Journal of Climate 28, 4637-4652.

Dimmitt, M.A. (1977). Status of the desert tortoise in the Colorado Desert. Proceedings symposium: The Desert Tortoise Council 1977, 46-53.

Duda, J.J., Krzysik, A.J. \& Freilich, J.E. (1999). Effects of drought on desert tortoise movement and activity. The Journal of Wildlife Management 63, 1181-1192.

Duda, J.J., Krzysik, A.J. \& Meloche, J.M. (2002). Spatial organization of desert tortoises and their burrows at a landscape scale. Chelonian Conservation and Biology 4, 387-397.

Ernst, C.H. \& Lovich, J.E. (2009). Turtles of the United States and Canada. John Hopkins University Press.

Flint, L.E., Flint, A.L., Mendoza, J., Kalansky, J. \& Ralph, F. (2018). Characterizing drought in California: new drought indices and scenario-testing in support of resource management. Ecological Processes 7, 1-13.

Freilich, J.E., Burnham, K.P., Collins, C.M. \& Garry, C.A. (2000). Factors affecting population assessments of desert tortoises. Conservation Biology 14, 1479-1489.

Germano, D.J., Bury, R., Esque, T., Fritts, T. \& Medica, P. (1994). Range and habitats of the desert tortoise. Biology of North American Tortoises 13, 73-84.

Griffin, D. \& Anchukaitis, K.J. (2014). How unusual is the 20122014 California drought? Geophysical Research Letters 41, 9017-9023.

Henen, B.T. (1997). Seasonal and annual energy budgets of female desert tortoises (Gopherus agassizii). Ecology 78, 283-296.

Henen, B.T. (2002). Reproductive effort and reproductive nutrition of female desert tortoises: essential field methods. Integrative and Comparative Biology 42, 43-50.

Henley, D.C. (2000). The land that God forgot: the saga of General George Patton's desert training camps: Western American History Series. Western Military History Association.

Hereford, R., Webb, R.H. \& Longpré, C.I. (2006). Precipitation history and ecosystem response to multidecadal precipitation variability in the Mojave Desert region, 18932001. Journal of Arid Environments 67, 13-34.

Kahn, P.F., Guyer, C. \& Mendonça, M.T. (2007). Handling, blood sampling, and temporary captivity do not affect plasma corticosterone or movement patterns of gopher tortoises (Gopherus polyphemus). Copeia 2007, 614-621.

Kinlaw, A. (1999). A review of burrowing by semi-fossorial vertebrates in arid environments. Journal of Arid Environments 41, 127-145.

Kinlaw, A. \& Grasmueck, M. (2012). Evidence for and geomorphologic consequences of a reptilian ecosystem engineer: the burrowing cascade initiated by the gopher tortoise. Geomorphology 157, 108-121.

Lathrop, E.W. (1983). Recovery of perennial vegetation in military maneuver areas, In Environmental Effects of OffRoad Vehicles, 265-277. Webb, R.H. \& Wilshire, H.G. (Eds.). New York, New York, USA: Springer Verlag New York.
Lips, K.R. (1991). Vertebrates associated with tortoise (Gopherus polyphemus) burrows in four habitats in south-central Florida. Journal of Herpetology 25, 477-481.

Lovich, J.E. \& Daniels, R. (2000). Environmental characteristics of desert tortoise (Gopherus agassizii) burrow locations in an altered industrial landscape. Chelonian Conservation and Biology 3, 714-721.

Lovich, J.E., Ennen, J.R., Agha, M. \& Gibbons, J.W. (2018a). Where have all the turtles gone and why does it matter? Bioscience 68, 771-781.

Lovich, J.E., Puffer, S.R., Agha, M., Ennen, J.R., Meyer-Wilkins, K., Tennant, L.A., Smith, A.L., Arundel, T.R., Brundige, K.D. \& Vamstad, M.S. (2018b). Reproductive output and clutch phenology of female Agassiz's desert tortoises (Gopherus agassizii) in the Sonoran Desert region of Joshua Tree National Park. Current Herpetology 37, 40-57.

Lovich, J.E., Yackulic, C.B., Freilich, J., Agha, M., Austin, M., Meyer, K.P., Arundel, T.R., Hansen, J., Vamstad, M.S. \& Root, S.A. (2014). Climatic variation and tortoise survival: Has a desert species met its match? Biological Conservation 169, 214-224.

Lowe, C.H., Lardner, P.J. \& Halpern, E.A. (1971). Supercooling in reptiles and other vertebrates. Comparative Biochemistry and Physiology Part A: Physiology 39, 125-135.

Luckenbach, R.A. (1982). Ecology and management of the desert tortoise (Gopherus agassizii) in California. North American Tortoises: Conservation and Ecology. US Fish and Wildlife Service, Wildlife Research Report 12, 1-38.

Mack, J.S., Berry, K.H., Miller, D.M. \& Carlson, A.S. (2015). Factors affecting the thermal environment of Agassiz's desert tortoise (Gopherus agassizii) cover sites in the central Mojave Desert during periods of temperature extremes. Society for the Study of Amphibians and Reptiles 49, 405-414.

Murphy, R.W., Berry, K.H., Edwards, T., Leviton, A.E., Lathrop, A. \& Riedle, J.D. (2011). The dazed and confused identity of Agassiz's land tortoise, Gopherus agassizii (Testudines, Testudinidae) with the description of a new species, and its consequences for conservation. ZooKeys 113, 39-71.

Nagy, K.A. \& Medica, P.A. (1986). Physiological ecology of desert tortoises in southern Nevada. Herpetologica 42, 73-92.

Nobel, P.S. \& Linton, M.J. (1997). Frequencies, microclimate and root properties for three codominant perennials in the northwestern Sonoran Desert on north- vs south-facing slopes. Annals of Botany 80, 731-739.

Noy-Meir, I. (1973). Desert ecosystems: environment and producers. Annual Review of Ecology and Systematics 4, 25-51.

Noy-Meir, I. (1974). Desert ecosystems: higher trophic levels. Annual Review of Ecology and Systematics 5, 195-214.

Nussear, K.E., Esque, T.C., Haines, D.F. \& Tracy, C.R. (2007). Desert tortoise hibernation: temperatures, timing, and environment. Copeia 2007, 378-386.

Parmesan, C., Root, T.L. \& Willig, M.R. (2000). Impacts of extreme weather and climate on terrestrial biota. Bulletin of the American Meteorological Society 81, 443-450.

Peterson, C.C. (1996). Anhomeostasis: seasonal water and solute relations in two populations of the desert tortoise (Gopherus agassizii) during chronic drought. Physiological Zoology 69, 1324-1358. 
Prose, D.V. (1985). Persisting effects of armored military maneuvers on some soils of the Mojave Desert. Environmental Geology and Water Sciences 7, 163-170.

Rautenstrauch, K., Rakestraw, D., Brown, G., Boone, J. \& Lederle, P. (2002). Patterns of burrow use by desert tortoises (Gopherus agassizii) in southcentral Nevada. Chelonian Conservation and Biology 4, 398-405.

Rautenstrauch, K.R., Rager, A.L. \& Rakestraw, D.L. (1998). Winter behavior of desert tortoises in southcentral Nevada. The Journal of Wildlife Management 62, 98-104.

Riedle, J.D., Averill-Murray, R.C., Lutz, C.L. \& Bolen, D.K. (2008). Habitat use by desert tortoises (Gopherus agassizii) on alluvial fans in the Sonoran Desert, south-central Arizona. Copeia 2008, 414-420.

Rosenberg, N.J., Blad, B.L. \& Verma, S.B. (1983). Microclimate: the biological environment. John Wiley \& Sons.

Sah, P., Nussear, K.E., Esque, T.C., Aiello, C.M., Hudson, P.J. \& Bansal, S. (2016). Inferring social structure and its drivers from refuge use in the desert tortoise, a relatively solitary species. Behavioral Ecology and Sociobiology 70, 12771289.

Stager, R.D., Roundy, E., Brackley, G., Leonard, S. \& Lato, L. (2017). Case study: using soil survey to help predict Sonoran desert tortoise population distribution and densities. Rangelands 39, 97-111.
Walde, A.D., Currylow, A. \& Walde, A.M. (2015). Discovery of a new burrow associate of the desert tortoise (Gopherus agassizii), the long-nosed leopard lizard (Gambelia wislizenii). Herpetology Notes 8, 107-109.

Warren, R.J. (2008). Mechanisms driving understory evergreen herb distributions across slope aspects: as derived from landscape position. Plant Ecology 198, 297-308.

Woodbury, A.M. \& Hardy, R. (1948). Studies of the desert tortoise, Gopherus agassizii. Ecological Monographs 18, 145-200.

Woodhouse, C.A. (1997). Winter climate and atmospheric circulation patterns in the Sonoran Desert region, USA. International Journal of Climatology: A Journal of the Royal Meteorological Society 17, 859-873.

Zimmerman, L.C., O'Connor, M.P., Bulova, S.J., Spotila, J.R., Kemp, S.J. \& Salice, C.J. (1994). Thermal ecology of desert tortoises in the eastern Mojave Desert: seasonal patterns of operative and body temperatures, and microhabitat utilization. Herpetological Monographs 8, 45-59. 